\title{
The Static and Fatigue Behavior of AlSiMg Alloy Plain, Notched, and Diamond Lattice Specimens Fabricated by Laser Powder Bed Fusion
}

\author{
Hugo Soul $^{+}$(D), Patrick Terriault and Vladimir Brailovski * \\ Department of Mechanical Engineering, Ecole de Technologie Superieure, 1100, Notre-Dame Street West, \\ Montreal, QC H3C 1K3, Canada; hugo.soul@cab.cnea.gov.ar (H.S.); patrick.terriault@etsmtl.ca (P.T.) \\ * Correspondence: vladimir.brailovski@etsmtl.ca; Tel.: +1-514-396-8594 \\ † Presently with Physics of Metals, Centro Atómico Bariloche, Bustillo 9500, San Carlos de Bariloche, \\ Río Negro, 8400, Argentina.
}

Received: 6 March 2018; Accepted: 17 April 2018; Published: 20 April 2018

\begin{abstract}
The fabrication of engineered lattice structures has recently gained momentum due to the development of novel additive manufacturing techniques. Interest in lattice structures resides not only in the possibility of obtaining efficient lightweight materials, but also in the functionality of pre-designed architectured structures for specific applications, such as biomimetic implants, chemical catalyzers, and heat transfer devices. The mechanical behaviour of lattice structures depends not only the composition of the base material, but also on the type and size of the unit cells, as well as on the material microstructure resulting from a specific fabrication procedure. The present work focuses on the static and fatigue behavior of diamond cell lattice structures fabricated from an AlSiMg alloy by laser powder bed fusion technology. In particular, the specimens were fabricated with three different orientations of lattice cells-[001], [011], [111]—and subjected to static tensile testing and force-controlled pull-pull fatigue testing up to $1 \times 10^{7}$ cycles. In parallel, the mechanical behavior of fully dense plain and notched tensile specimens was also studied and compared to that of their lattice counterparts. Results showed a significant effect of the cell orientation on the fatigue lives: specimens oriented at [001] were $~ 30 \%$ more fatigue-resistant than specimens oriented at [011] and [111].
\end{abstract}

Keywords: laser powder bed fusion; lattice structures; cell orientation; fatigue

\section{Introduction}

Research works on cellular materials have been primarily motivated by the possibility of expanding the effective range of mechanical properties attainable with convectional materials via the fabrication of strong and stiff lightweight structures [1,2]. Their distinguishing characteristics depend on a specific mesoscale distribution of solid and void volumes, which can be either stochastic (foams) or periodically ordered (lattice structures). One of the advantages of the ordered structures is that a regular arrangement of the matter allows greater control of their macroscopic physical and mechanical behavior, which is especially important for long-term applications [3].

Developments experimented in recent years by additive manufacturing (AM) technologies have boosted the research in the field of lattice structures, thanks to the unique capacity of AM to fabricate complex engineered components, which would otherwise be unfeasible or prohibitively expensive [4]. Available AM technologies allow the production of engineered components from a variety of polymers, metallic alloys, and ceramic materials.

Interest in lattice structures resides not only in their potentially enhanced structural performances, but also in the possibility of tailoring their functionality for different applications. For example, 
in the field of biomedicine, there is a strong interest in the development of engineered lattice structures capable of mimicking the mechanical behavior of bones and providing strong bonding with surrounding tissues via the bone tissue ingrowth [5,6]. Moreover, the high surface/volume ratio of lattice structures makes them especially appropriate for high-efficiency heat exchangers [7] and catalyzers [8]. The power requirements for pumping fluids and gases through the lattices are reduced as compared to traditional foams due to their periodicity and, therefore, their higher permeability. The possibility of conformal cooling of insert parts in injections molds also constitutes an interesting opportunity [9]. Finally, lattice structures can be used to enhance the damping and energy-absorbing properties of engineered systems $[10,11]$.

Predicting the functional and structural performances of mechanical components made entirely or partially of lattice structures requires that the mathematical models of such components be built and validated. For the mechanical properties, analytical models exist, allowing the prediction of the elastic moduli, yield, and ultimate stresses of regular lattice structures as functions of the cell type, porosity, and properties of the base material $[1,12,13]$. Usual assumptions consider lattice structure struts as bars transmitting normal efforts (stretching dominated behavior) or beams transmitting bending moments (bending dominated behavior) [13-15]. The more three-dimensional the stress state becomes, as it occurs with relatively dense lattices, the more complicated the numerical methods applied for their modeling must be $[16,17]$. Besides attaining a comprehensive description of deformation mechanisms acting during loading, such a modeling allows the elaboration of simplified constitutive laws by which the macroscopic behavior of lattice structures can be simulated. However, any numerical model must be thoroughly validated before it can be used with confidence, which justifies the need in extensive experimental studies of the mechanical behavior of lattice structures.

Given that almost every mechanical component is subjected to cyclic loading during its service life, the capacity to predict the fatigue resistance of lattice-containing components becomes particularly relevant. Likewise with convectional dense parts, the fatigue properties of lattice structures are strongly influenced by their microstructure (grain size, texture, phase state) and surface roughness. The layer-by-layer material deposition and localized melting phenomena, which take place during AM processing, result in a strong material anisotropy and in a high level of residual stresses, both effects strongly impacting the fatigue resistance of AM-built components [11,18-21]. Moreover, porosity and surface defects induced by the process are prone to trigger failure mechanisms like crack nucleation or plastic collapse. Therefore, to account for the influence of defects on the mechanical behavior of AM-built components, it is necessary to correlate their type, size, and distribution with the process parameters [22-25]. Another aspect to be accounted for is related to the resulting dimensions of the components. The strut thickness of the commonly designed lattice structures (some hundreds of microns) is comparable to the melting pool and the heat-affected zone along the process [23], whose sizes depend on laser power, spot size, layer thickness, and scanning speed. Additionally, surface roughness and dimensional accuracy of AM components depend on the powder particle size distribution, typically ranging from 20 to $60 \mu \mathrm{m}[23,24]$. In their statistical study, Sing et al. concluded that, while all the parameters mentioned affect the dimensions and, therefore, the mechanical properties of AM-built lattice structures [25], the laser power appears to be the most relevant one to be optimized.

The problem becomes even more complex when we consider that the mechanical response of lattice structures can also be orientation-dependent due to the intrinsic anisotropy of building blocks (cells). In this regard, Zhao et al. [26] studied the compressive fatigue lives of different lattice structures with relative densities ranging from 36 to $38 \%$. They differentiated the strut damage mechanism of bending from that of buckling, and suggested that the fatigue resistance of lattice structures could be improved if the cell struts were aligned along the loading direction. In another study of compressive fatigue of lattice structures with relative densities ranging from 11 to 34\%, Amin Yavari et al. [27] also argued that the fatigue properties of lattice structures depend on the angle between the cell struts and the loading direction. 
In both these works [26,27], it was found that the fatigue lives of cubic cell-based structures were superior to those of lattice structures with other cell geometries, such as the diamond, dodecahedron, or truncated cuboctahedron, with this outcome being mainly attributed to particular orientations of these structures during their testing. A similar conclusion on the particular significance of the lattice structure cell orientation with respect to the loading direction was also drawn by Wauthle et al. [28]. It should, however, be noted that, although the preceding studied exposed the importance of considering the cell orientation during loading, no systematic research was carried out with respect to the fatigue properties of differently oriented lattice structures.

Another point that must be mentioned is that most of the studies covering the fatigue resistance of lattice structures were carried out under compressive loads. In one of the scarce works on the tensile fatigue of lattice structures, Huynh et al. [29] highlighted the importance of accounting for the effective concentration factors in the estimation of maximum stresses occurring in these structures under loading.

To sum-up, the continuous efforts to predict the fatigue resistance of AM-built lattice structures needs to be supported by a comprehensive experimental database, which would also include results from other materials than the extensively studied Ti-based alloys.

In this work, the tensile static and fatigue mechanical behavior of diamond lattice structure specimens made from an AlSiMg alloy using laser powder bed fusion (L-PBF) is experimentally assessed. The testing specimens are fabricated with three different unit cell orientations with respect to the manufacturing and testing directions, to verify if a significant anisotropy is present in their mechanical behavior. In parallel with the lattice specimens, fully dense plain and notched tensile specimens made from the same material and using the same technology are characterized, and the results obtained compared, in order to reach a conclusion on the impact of lattices on the static and fatigue behavior of L-PBF-built components.

\section{Specimen Design, Material, Fabrication, and Structural and Dimensional Control}

\subsection{Specimen Design}

The modeling and numerical analysis of all the specimens of this study were realized using ANSYS Workbench 17.0 Software (Canonsburg, PA, USA, 2017). For the lattice specimens, their geometry was imported into ANSYS using an STL file generated by the MATLAB routine developed by Dumas et al. [30]. The MAGIC 17.02 software (Materialise, Belgium) was then applied to adapt the specimens to the manufacturing environment and add, if and where needed, support structures.

\subsection{Dense Specimens: Plain and Notched}

Although this work was mainly focused on lattice structures, the fully dense tensile specimens with plain and notched geometries were also fabricated with the objective of measuring the properties and the notch sensitivity of the base material.

The dimensions of the plain specimens (Figure 1a) were defined in agreement with the subsized ASTM E8/E8M tensile specimens. The notch tip of the notched specimens (Figure 1b) was designed with a radius of $0.2 \mathrm{~mm}$, the smallest radius that can be confidently manufactured using the EOS

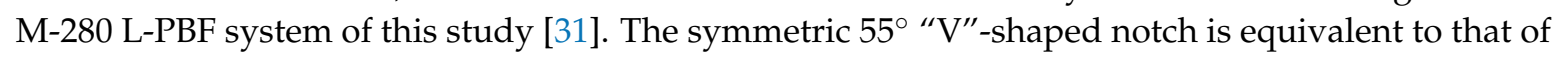
a "U"-shaped notch with an elastic stress concentration factor $K_{t}=4$ [32]. This notch angle does not require the use of internal supports, which allows keeping the as-manufactured surfaces unaltered.

Both the plain and the notched specimens were designed with the same working and total length, thickness, and minimum cross section. For the FE simulations, only one octave of their geometry was meshed. The mesh consisting of 10-node tetragonal elements was refined in the regions where stress gradients were expected. In Figure 1b, the building direction (BD) refers to the one in which successive layers of the material are added; this direction coincides with the tensile loading direction (LD). 


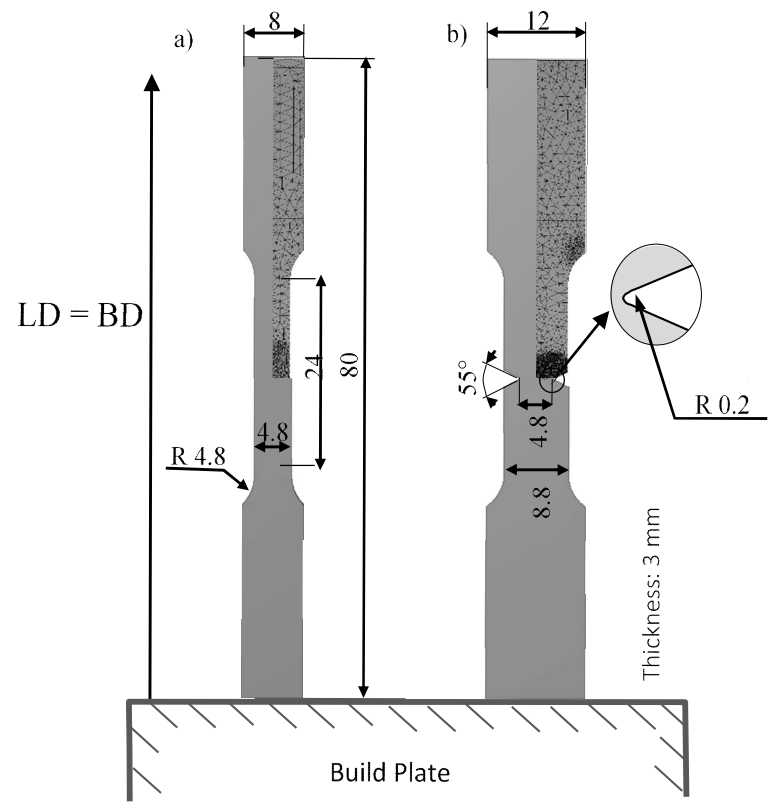

Figure 1. Sketches of the dense specimens: (a) plain (b) notched; BD and LD correspond to the building and loading directions, respectively; all dimensions are in $\mathrm{mm}$.

\subsection{Lattice Specimens}

\subsubsection{Definition of a Unit Cell}

In this work, a "diamond" cell geometry, which is similar to the carbon atoms arrangement in the case of the diamond state, is adopted for the lattice specimens. Lattice structures with the diamond cell geometries are being extensively implemented in the designing of biomedical implants thanks to their proven mechanical compatibility with bone tissues [27,33].

Although the diamond cells are less anisotropic than the other frequently used cell geometries (cubic, truncated octahedron, dodecahedron) [27], their mechanical response can be adjusted in benefit of a specific application by modifying their strut thickness, length, and loading direction [34]. Another advantage of diamond cells is that their overhang angle of $35.26^{\circ}$ shown in Figure 2a is high enough to allow their L-PBF fabrication without the need for internal supporting structures.

The diamond cell can be described as a spatial arrangement of nodes, separated from each other by a length $l$, and linked by struts, which transfer the external loads by normal, shear, bending, and torsion forces. Figure 2a depicts the basic cross-shaped substructure of such a diamond cell with its characteristic angles inscribed in a cube of edge $a$. The $X-Y-Z$ coordinate system is also shown, with respect to which any relevant direction can be referred. By alternating this crossed-shaped substructure with empty spaces, a cubic unit cell of length $2 a$ can be obtained (see Figure $2 b$ ).

This unit cell can finally be copied along the $X_{-}, Y_{-}$, and $Z$-axes to generate a lattice structure. Given the periodicity of this unit cell along the three axes, orthotropic macroscopic properties are expected. The diamond unit cell includes 16 struts and 18 nodes; however, considering the nodes shared with the neighboring unit cells, the net number of nodes is 8 . This particular geometric design corresponds to that developed by Dumas et al. [30].

The struts are modelled with hexagonal cross sections instead of circular cross sections, and the nodes, with truncated tetrahedrons, instead of spheres. As such, the resulting volume can be represented by a limited number of triangular facets in an STL file format, which enables the modelling of lattice structures comprising a very large number of cells. Figure $2 c, d$ respectively depicts a modelled crossed-shape substructure and a cubic unit cell with two independent parameters, which fully define their geometry: the pore diameter $d$ and the beam thickness $t$ (see $[30,35]$ for more details). The pore 
diameter $d$, indicated in Figure 2d, corresponds to the largest sphere, which can be fitted inside the lattice. The following relationship between $l, t$, and $d$ can be derived from a geometrical analysis (not included here):

$$
l=\frac{d}{2}+\frac{5 t}{6 \sqrt{2}}
$$

The size of the cubic cell $a$ and the strut length $l$ are related as follows:

$$
a=2 l \cos \left(35.26^{\circ}\right) \cos \left(45^{\circ}\right)=1.155 l
$$

The relative cell density $\delta$ can be calculated by dividing a total volume of the matter, i.e., that of 16 beams and 8 truncated tetrahedrons, by a volume of the cubic cell, $8 a^{3}$. Additionally, by a simple geometrical analysis, this relation can be reduced to the following expression, depending only on the ratio $t / l$ :

$$
\delta=1.125\left(\frac{t}{l}\right)^{2}-0.5415\left(\frac{t}{l}\right)^{3}
$$

In this study, the parameters selected as inputs for the MATLAB lattice modeling routine are the strut thickness $t=0.6 \mathrm{~mm}$ and the pore diameter $d=0.8 \mathrm{~mm}$. According to Equations (1)-(3), these parameters correspond to the cell size $a=0.807 \mathrm{~mm}$ and the relative lattice density $\delta=0.440$.

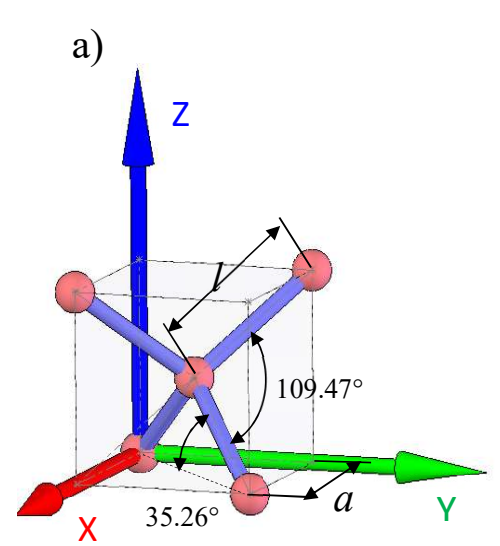

c)

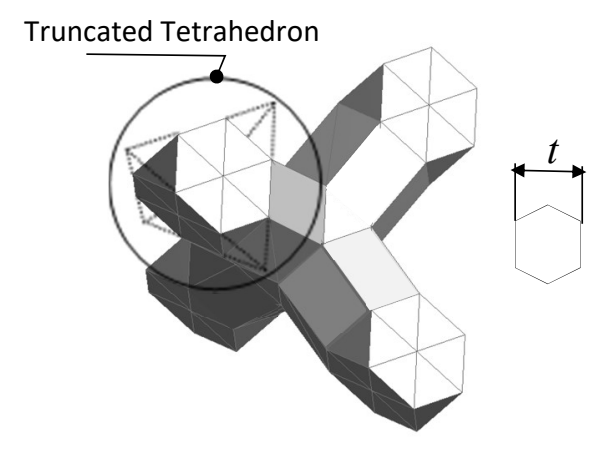

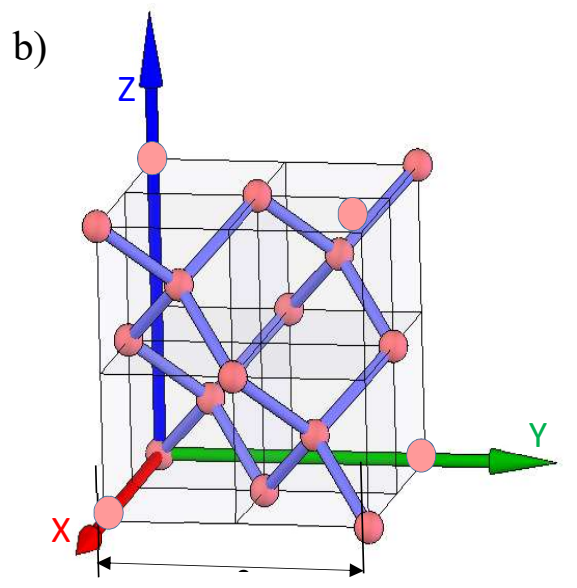

d)

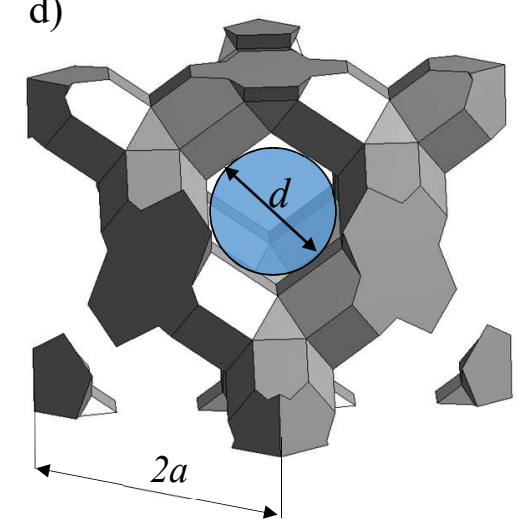

Figure 2. Diamond cell adopted for the lattice structure: (a) cross-shaped substructure made of nodes and struts; (b) periodic cubic unit cell; (c) modeled cross-shaped unit cell; (d) modeled periodic cubic unit cell. 


\subsubsection{Design of Lattice Specimens}

Tensile specimens with lattice structures were designed by merging a central lattice-containing region, which is basically a prismatic volume with an overall cross section close to a square, to two fully dense end regions (grip regions). In order to avoid undesirable fractures on the interfaces between the constant-density central lattice region and the fully dense end regions, the lattice and the dense regions were connected via the density gradient transition regions (Figure 3a). The lattice specimens were fabricated with three different cell orientations designated as [001], [011] and [111]. This Miller index notation indicates the direction of the loading axis (LD) with respect to the cell reference axis system defined in Figure 2a,b. The central (constant density) region of the [001] lattice contains $13 \times$ $13 \times 13$ cross-shaped cells. For the other orientations, this central region was rotated and delimited to preserve the constant lattice density of $\delta \approx 0.440$.



Figure 3. Tensile specimens of differently oriented diamond cell lattice structures: (a) principal dimensions and description of the different regions of [001]-oriented specimens (dimensions in $\mathrm{mm}$ );

(b) CAD models and schematic representations of the periodic unit cells of this study.

In Figure $3 b$, the specimens of each orientation (CAD models) are represented along with the corresponding cell coordinate systems. A closer view of a prismatic periodic unit cell for each of the three lattice orientations is given in Figure $3 b$, with their respective dimensions aligned with the specimen edges. Note that some of the [011]-oriented specimen struts are oriented horizontally, their overhang angle being equal to $0^{\circ}$. For the [111]-oriented specimens, this angle corresponds to $19.47^{\circ}$. As it was the case for the fully dense specimens, the lattice structures are positioned in such a way that their manufacturing and loading directions coincide. 


\subsection{Material and Fabrication}

All the specimens were manufactured using a laser powder bed fusion EOS 280 (EOS Gmbh, Germany) system, AlSi10 EOS powder, and the configuration parameter set provided by the manufacturer for this material, AlSi10Mg_Speed 1.0. An image of the build plate with the dense and lattice specimens is shown in Figure 4. The total printing procedure required $78 \mathrm{~h}$. After the printing, a stress relief heat treatment $\left(300^{\circ} \mathrm{C}, 2 \mathrm{~h}\right)$ was applied to the specimens while they were still on the build plate; the specimens were then cut off with a mechanical saw.

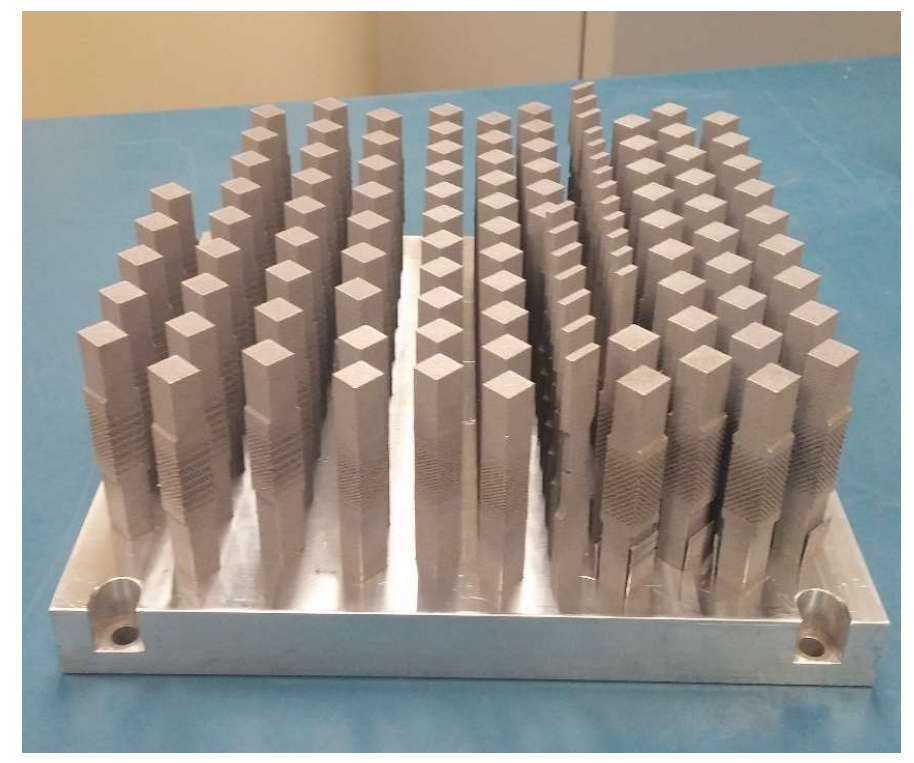

Figure 4. Printed specimens on the build plate.

\subsection{Micro-Tomography Analysis of the Dense and Lattice Specimens}

One dense and one lattice specimen of each orientation were scanned using a Nikon XT H225 X-ray micro-tomography system (Nikon, Brighton, MI, USA) configured with $200 \mathrm{kV}-60 \mu \mathrm{A}$ and a Cu filter. The specimens were scanned over a total length of $25 \mathrm{~mm}$ with a resolution of $12 \mu \mathrm{m}$, and their 3D models were generated using VGStudio Max 3.0 (2016) software.

One of the problems faced by the AM technologies is related to the internal porosity of the printed material, which is also commonly observed in casting [36]. Excessive porosity levels can be prejudicial to mechanic properties, especially those related to dynamic loads. Mechanical elements that are exposed to cyclic or impact loadings can receive post-processing treatment, such as hot isostatic pressing (HIP), to reduce their porosity level. If it is not possible or justifiable to apply such a treatment, it is important at least to characterize the level of internal porosity in the manufactured parts. A picture showing an example of an internal pore is given in Figure 5a. By using the VGStudio Max 3.0 software porosity analysis tool, the histograms of pore count as a function of the pore equivalent diameter were generated for the dense specimen and for the lattice specimens of different orientations (see Figure $5 b$ ). The relative level of porosity calculated for the dense and lattice specimens resulted in values smaller than $0.24 \%$.

Next, the 3-D reconstructed images of lattice specimens are shown in Figure 6a. Just one half of each specimen was digitalized. The volumes shown in Figure $6 \mathrm{~b}$ were extracted from the bulk of each digital reconstruction, and correspond to the periodic unit cell arrangement shown in Figure 3c. Although the CAD models and the manufactured specimens show an acceptable conformity at the macroscopic level (Figure 3b vs. Figure 6a), a significant surface roughness and an absence of net edges on the hexagonal struts and truncated tetrahedrons can clearly be seen (Figure 6b). Additionally, a certain quantity of semi-welded particles on the surface of the specimens can be observed in 
Figure $6 \mathrm{~b}$; they were sintered to the structure during the L-PBF processing. It therefore became difficult to precisely assess the geometrical features of these lattice structures, such as the strut thickness and length. Moreover, since the length/thickness ratio of the struts was rather small, it was not deemed practical to perform a detailed analysis of processing-induced dimensional deviations similar to that carried out by Liu et al. [37].

a)

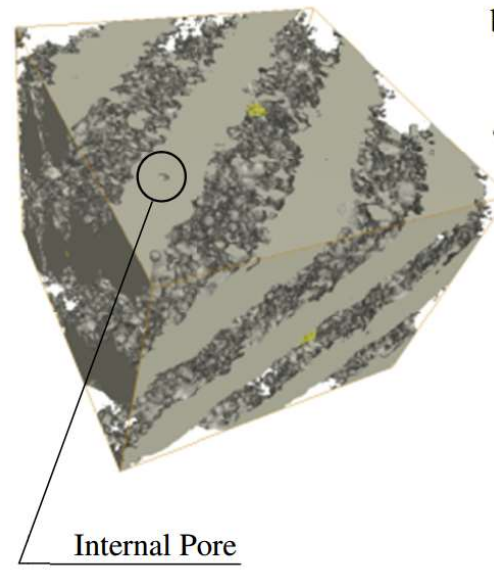

b)

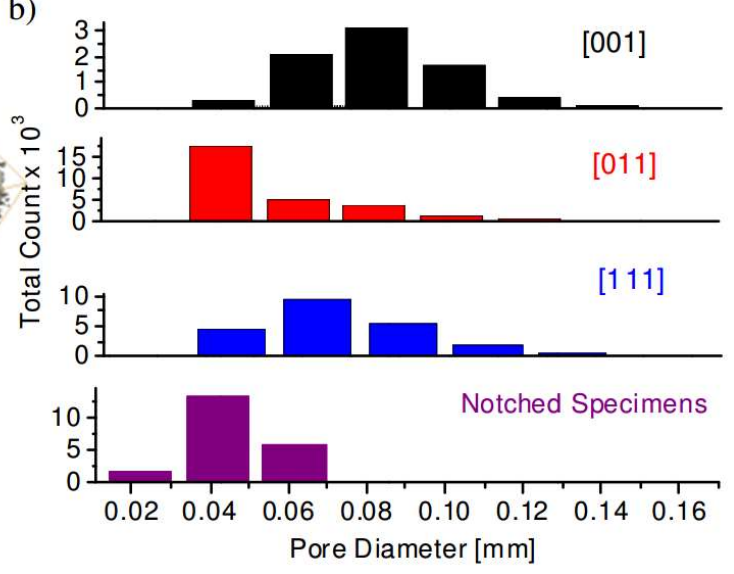

Figure 5. Internal porosity analysis of the lattice and dense notched specimens: (a) example of an internal pore found in the material; (b) pore distribution histograms for the lattice and dense specimens.

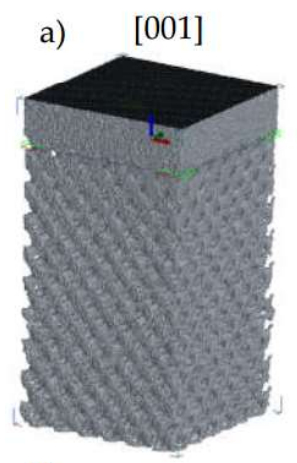

b)

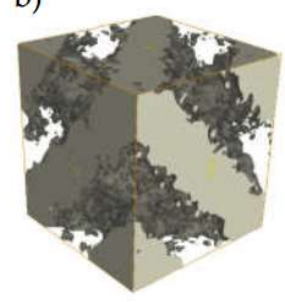





[111]
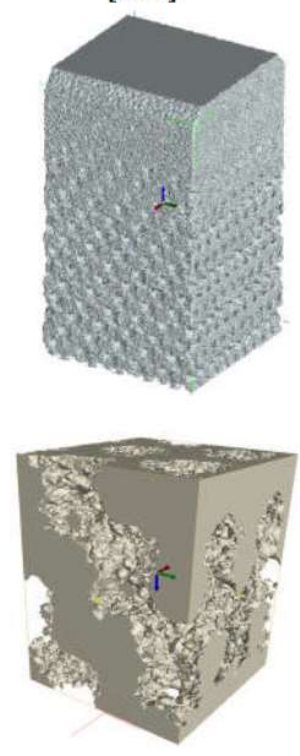

Figure 6. 3-D reconstructed images of the differently oriented lattice specimens: (a) illustrations of the entire digitalized area; (b) selected regions corresponding to the periodic unit cell arrangements.

Instead, the dimensional deviations analysis was performed by applying the following global approach. Variations of the net cross-section area $A$ along the longitudinal axes of the L-PBF-built specimens were calculated using their 3-D reconstructed models and then compared to the corresponding CAD values. To carry out these measurements, an elementary slice with a thickness of $\Delta h=0.15 \mathrm{~mm}$ was defined in the VGStudio Max 3.0 reconstruction software as a region of interest. The volume of the slice, calculated by the software, was then divided by its thickness, and the average cross-section area was reported. In the constant porosity region of all the specimens, the spacing 
between the measurement positions was reduced to $0.02 \mathrm{~mm}$, to allow the periodic variation to be clearly addressed. For the rest of the measurements, a larger spacing $(0.25 \mathrm{~mm})$ was used to reduce the calculation time.

Although the ANSYS Workbench allows for a direct measurement of cross sections of CAD models, the same procedure using VGStudio Max 3.0 software was repeated with the CAD models, for the sake of consistency. For all three-cell orientations, the so-measured cross-section areas are plotted in Figure 7a,c,e, where the dense, gradient, and constant porosity regions of the specimens can clearly be identified. Small very-high-density lattice regions were also printed between the transition and the fully dense regions, as depicted in the diagrams.

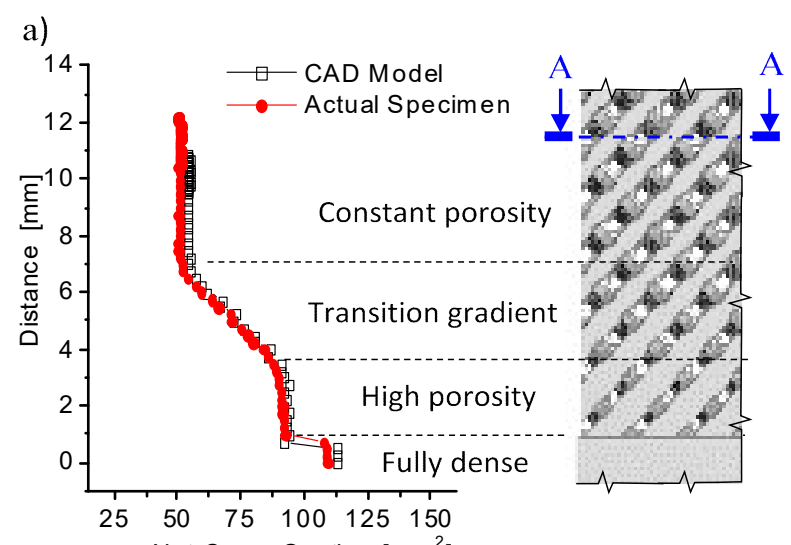

b) $\quad$ Section A-A

c)
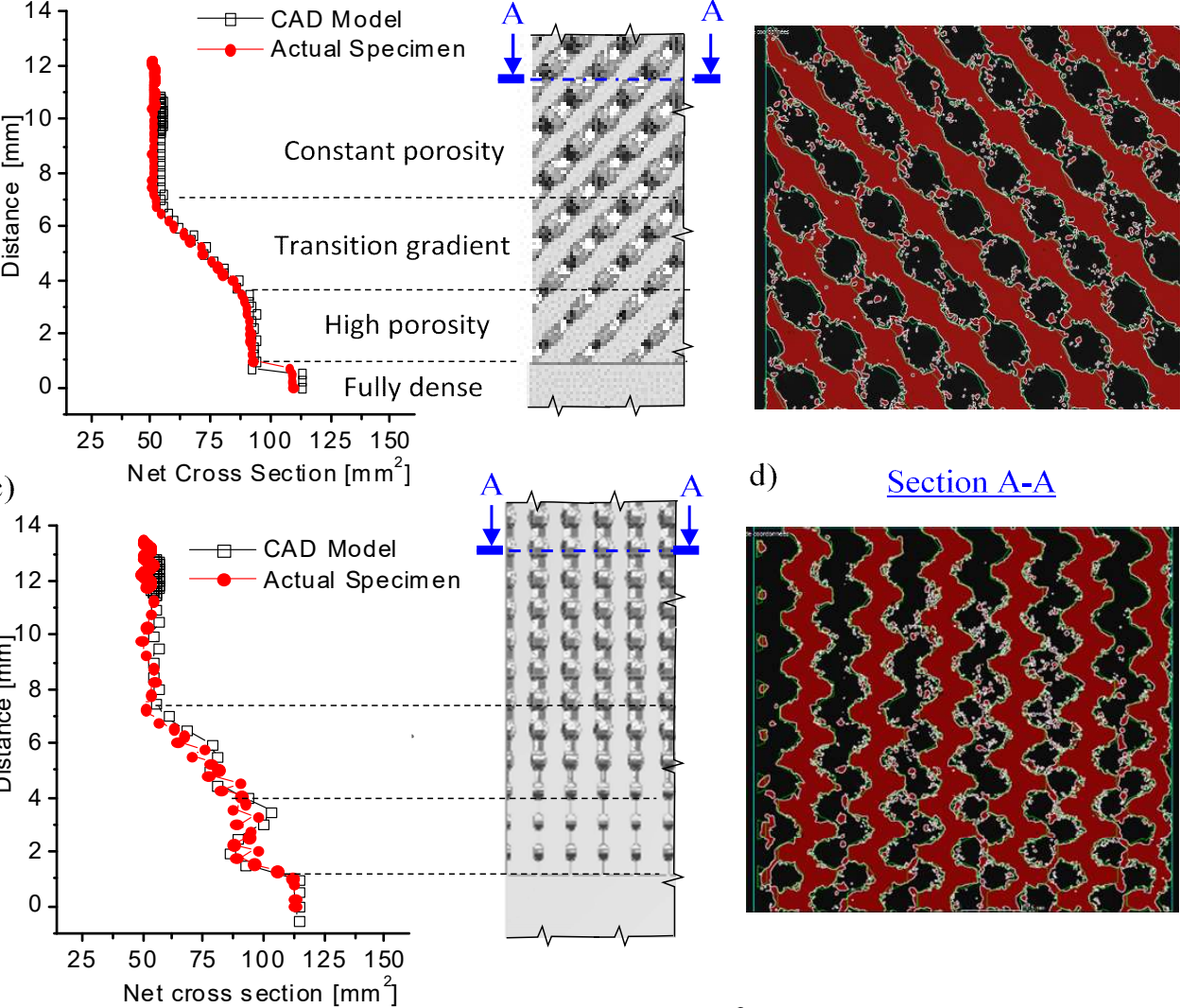

d) Section A-A


f)

Section A-A

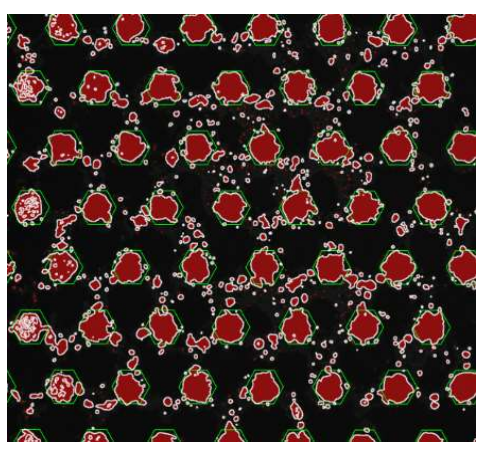

Figure 7. Evaluation of the net solid cross sections of the differently oriented lattice specimens along LD: $(\mathbf{a}, \mathbf{c}, \mathbf{e})$ plots of the net solid cross sections for the three orientations; $(\mathbf{b}, \mathbf{d}, \mathbf{f})$ details of the cross sections of each orientation compared with the contour lines of the CAD model. 
As observed, the cross sections of the actual specimens (filled areas) present systematically lower surface area values than those of their CAD models (solid curves). The plots show also that the periodic variations of the net sections are the most pronounced for the [111] orientation. Figure $7 \mathrm{~b}, \mathrm{~d}, \mathrm{f}$ corresponds to the images of the A-A cross sections extracted from the positions where they reach their minimum values. Green lines indicate the contours of the CAD models.

The measurements made in the central regions of the lattice specimens were utilized for the evaluation of their minimum net cross-section areas, $A_{\min C A D}$ and $A_{\min A S}$, and their relative densities, $\delta_{C A D}$ and $\delta_{A S}$. Subindex labels $C A D$ and $A S$ indicate the values corresponding to the CAD models and actual specimens, respectively. The relative densities $\delta_{C A D}\left(\delta_{A S}\right)$ were calculated by adding $N$ values of $A$ obtained through one periodic distance along the axial direction, being then normalized with the bounding (gross) cross-section $A_{g r}$.

$$
\bar{\delta}_{r e l}=\frac{\sum_{1}^{N} A}{A_{g r} N}
$$

Table 1 summarizes the values of the gross cross sections $A_{g r}$, the minimum net cross sections $A_{\text {min }}$, and the relative densities $\delta$.

Table 1. Gross and net cross sections and densities for the CAD models and the actual specimens.

\begin{tabular}{cccc}
\hline & [001] & [011] & [111] \\
\hline$A_{g r C A D}, \mathrm{~mm}^{2}$ & 113 & 114 & 143 \\
$A_{g r A S}, \mathrm{~mm}^{2}$ & 110 & 113 & 143 \\
$A_{\min C A D}, \mathrm{~mm}^{2}$ & 54.2 & 53.6 & 33.9 \\
$A_{\min A S}, \mathrm{~mm}^{2}$ & 51.0 & 49.6 & 27.5 \\
$A_{\min A S} / A_{\min C A D}$ & 0.94 & 0.925 & 0.811 \\
$\delta_{C A D}$ & 0.483 & 0.481 & 0.475 \\
$\delta_{A S}$ & 0.455 & 0.452 & 0.454 \\
\hline
\end{tabular}

\section{Experimental Program and Results}

Static and fatigue tensile testing with plain and notched fully dense specimens, and with specimens bearing differently oriented diamond lattice structures was carried out using an MTS 858 Minibionix II system equipped with a $15 \mathrm{kN}$ load cell. The forces and displacements were recorded using a load cell and the position sensor (LVDT) of the system.

The fatigue testing was performed at room temperature at a $15 \mathrm{~Hz}$ frequency, and consisted in a force controlled tension-tension cycling up to a run-out value of $10^{6}$ cycles for dense specimens and $10^{7}$, for lattice specimens. For all the tests, the ratio of the minimum to the maximum force (stress) in a cycle, $\mathrm{R}$, was set to 0.1 . For each fatigue testing run, the maximum stress applied in a cycle, $\sigma_{\max }$ was set as a fraction of the corresponding value of the yield stress, $\sigma_{y}$. Fatigue testing of fully dense plain specimens was performed for $1.2,1,0.8,0.6,0.5$, and $0.4 \sigma_{y}$ fractions, while the notched specimens were tested for $1.2,1,0.8,0.6,0.5,0.4$, and $0.2 \sigma_{y}$ fractions. For the lattice specimens, the $\sigma_{y}$ fractions were $1.2,1,0.8,0.6,0.4,0.3$, and 0.2 . For the fully dense plain and notched specimens, one specimen for each stress level was fatigue-tested. For the lattice specimens, two tests for each level of maximum stresses were performed, except for the fractions 0.3 and 0.2 , where a single fatigue test was carried out.

Finally, for some of the tests performed, a digital image correlation (DIC) system (GOM Aramis) was used for the acquisition of the displacement fields. 


\subsection{Monotonic Tensile Testing}

\subsubsection{Fully Dense Specimens}

\section{Plain Specimens}

Four plain specimens were subjected to tensile testing: Specimens \#1 and \#4 were strained up to failure, \#3 was loaded and unloaded, and \#2 was loaded, unloaded, and strained up to failure. The force-displacement diagrams obtained during testing of plain specimens are shown in Figure 8a, and they reflect almost perfect inter-specimen repeatability. Failure occurred with almost no localized area reduction, as seen in the picture included in Figure 8a.
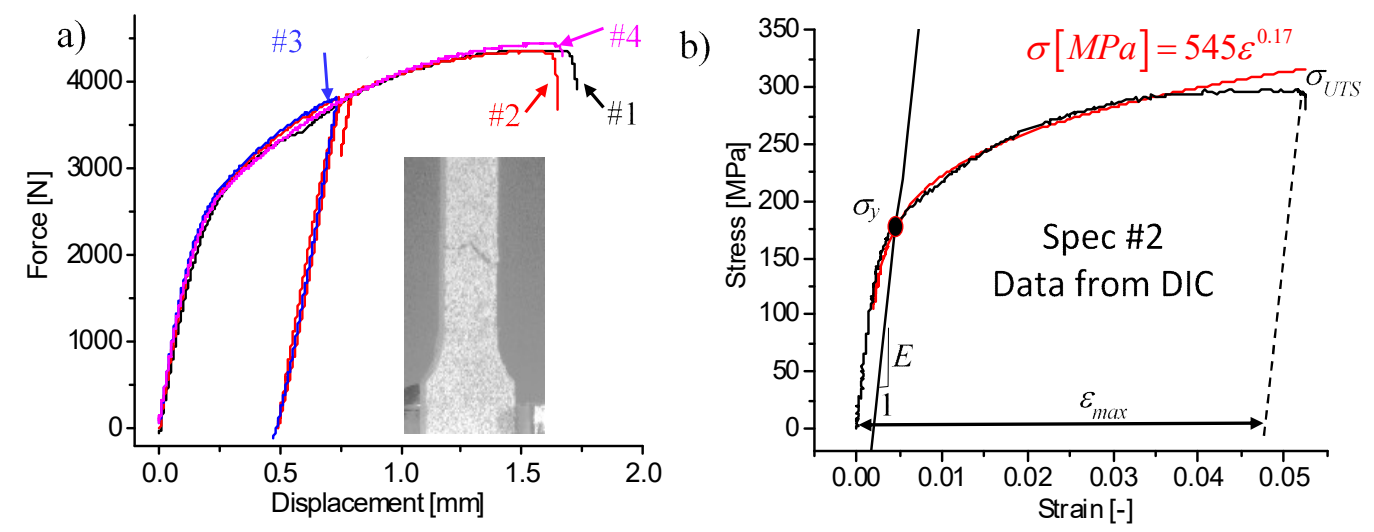

Figure 8. Tensile testing of plain specimens: (a) force-displacement diagrams of Specimens \#1 and \#4 strained to failure, \#3 loaded and unloaded, and \#2 loaded, unloaded, and strained to failure; (b) experimentally measured and Hollomon-approximated stress-strain diagrams of Specimen \#2.

Using the displacement fields measured inside a $5 \mathrm{~mm}$ central gage length of one of the plain specimens (DIC-ARAMIS), the stress-strain diagram was built (Figure 8b), and the Young's modulus $E$, the yield stress $\sigma_{y}$, the ultimate tensile strength $\sigma_{U T S}$, and the elongation at break $\varepsilon_{m a x}$ were calculated and are shown in Table 2. These results are comparable to those obtained with the same alloy subjected to a similar heat treatment by Geng et al. [38]: the differences in the $E$ and $\sigma_{U T S}$ values are less than $4 \%$, while that in the $\sigma_{y}$ values, less than $20 \%$. The red curve in Figure $8 \mathrm{~b}$ corresponds to the stress-strain diagram fitted with an exponential expression (Hollomon fitting). This expression was utilized as a material law for the FE simulations presented below.

\section{Notched Specimens}

Figure 9a includes the force-displacement diagrams obtained during monotonic tensile testing of three notched specimens, \#5, \#6 and \#7, along with the diagram of a selected plain specimen. As in the case of plain specimens, no significant variations were observed among the tested notched specimens. The same experiment was then FE-simulated using the model of the notched specimen shown in Figure $1 b$, and the FE-calculated stress-strain diagram is superposed in Figure $9 b$ on the DIC-measured stress-strain diagram (a gage length of $3.6 \mathrm{~mm}$ was used for both the FE simulations and the DIC measurements). It can be seen that the tensile behavior of the notched specimens is reproduced by the FE simulations with acceptable agreement. 

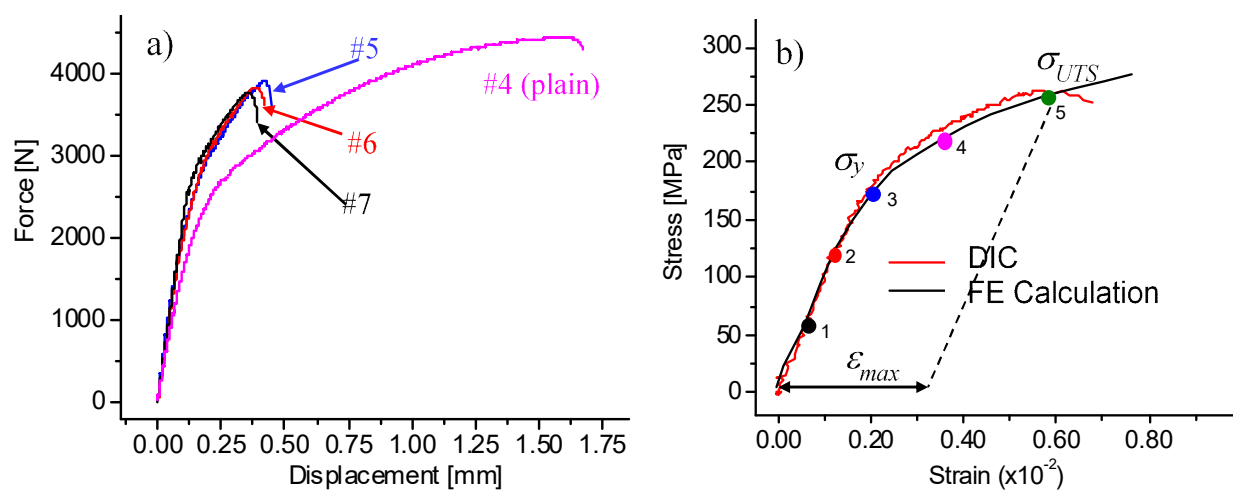

Figure 9. Tensile testing of notched specimens: (a) force-displacement diagrams obtained for three notched and one plain specimens; (b) stress-strain diagram of Specimen \#7 (simulation and testing); numbers 1 to 5 indicate different reference points along the stress-strain plot.

Since, in this case, the strain along the gage length was non-uniform, it was not possible to calculate the elastic modulus. However, a mean yield stress of $193 \mathrm{MPa}$, associated with the generalized plastic deformation in the notched zone, was measured at the point where the force-displacement diagram clearly departs from its linear region. The mean ultimate tensile strength of $266 \mathrm{MPa}$ was also measured in the same zone of the specimen. Note that the mean yield stress for the notched specimens was $11 \%$ higher, while the mean ultimate tensile strength $12.5 \%$ lower than those measured for their plain counterparts (Table 2).

Table 2. Mechanical properties of fully dense LPBF-built AlSi10Mg specimens.

\begin{tabular}{ccccc}
\hline & $\begin{array}{c}\text { Young's Modulus } \\
\boldsymbol{E} \mathbf{( G P a )}\end{array}$ & $\begin{array}{c}\text { Yield Stress 0.2\% } \\
\sigma_{y}(\mathbf{M P a})\end{array}$ & $\begin{array}{c}\text { Ultimate Tensile } \\
\text { Strength } \sigma_{\text {UTS }}(\mathbf{M P a})\end{array}$ & $\begin{array}{c}\text { Elongation at } \\
\text { Break } \boldsymbol{\varepsilon}_{\max }(\mathbf{\%})\end{array}$ \\
\hline Plain specimens & $67 \pm 2$ & $180 \pm 2$ & $304 \pm 2$ & $4.7 \pm 0.6$ \\
Notched specimens & - & $193 \pm 4$ & $266 \pm 2$ & $0.5 \pm 0.1$ \\
\hline
\end{tabular}

Next, the FE model of the notched specimens was used for the numerical evaluation of an effective stress concentration factors $\left(K_{e}\right)$ associated with the imposed notch geometry and the measured material behavior. Each plot in Figure 10a corresponds to the evolution of the normal axial stress along a straight path that goes from the root of the notch to the center of the specimen (Figure 10b), for each of the 5 levels of the mean stresses incrementally shown on the stress-strain diagram in Figure 9b. It can be seen that the normal stress reaches its maximum, $\sigma_{\max }$, at a certain distance from the notch root and then decreases to approach the colored horizontal straight lines. Each straight line corresponds to the value of a mean stress $\bar{\sigma}$ for each loading level from 1 to 5 (an initial dense specimen net cross section of $14.4 \mathrm{~mm}^{2}$ was used for these calculations). The effective stress concentration factor for each level of loading was then calculated as

$$
K_{e}=\frac{\sigma_{\max }}{\bar{\sigma}}
$$

It can be observed in Figure 10a that the greater the load applied to the specimen, the lower the effective stress concentration factor caused by the notch; this phenomenon reflects stress relaxation in the vicinity of the notch due to local plasticity. Since the stress concentration factor remains significantly high even in the zone of plastic deformation (>2.33), the mechanical behavior of this material can be considered highly notch-sensitive. 


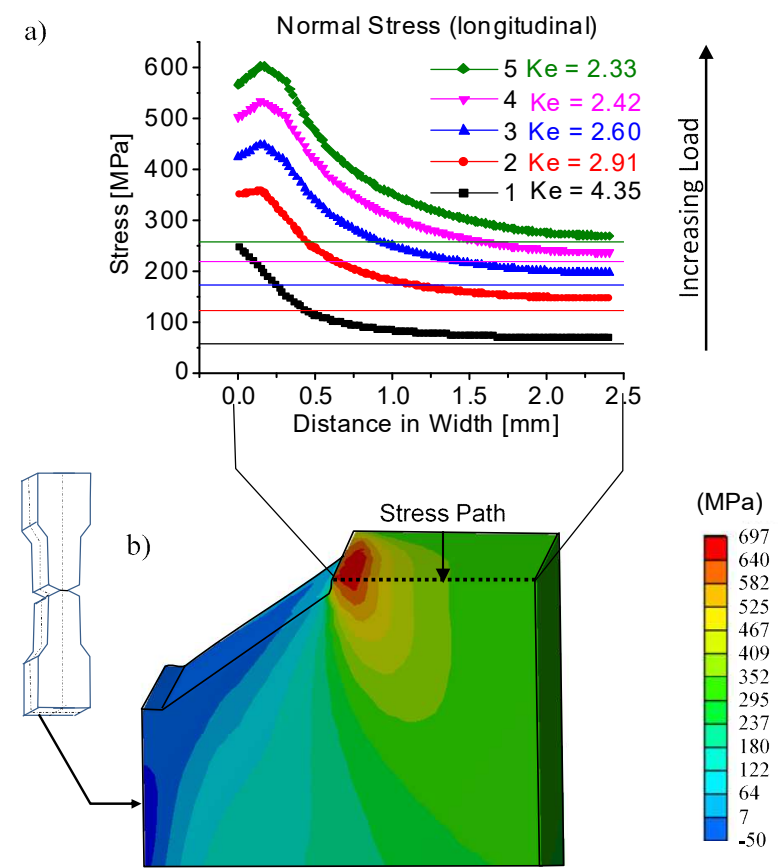

Figure 10. FE-calculated effective stress concentration factors: (a) normal stress distribution in the loading direction along a path from the notch root to the center of the specimen as a function of the applied load 1, 2, 3, 4, and 5; (b) FE-calculated normal stress field in the vicinity of the notch corresponding to Level 5 of the applied load.

\subsubsection{Lattice Specimens}

The force-displacement diagrams obtained with specimens having different diamond cell orientations are plotted in Figure 11a. To measure uniaxial strains using the DIC technique, discrete targets were glued to the surface of these specimens in their constant density regions. The uniaxial stresses were calculated by dividing the forces applied to the specimens by their gross cross-section areas $A_{\text {graS }}$ collected in Table 1. This definition of stress corresponds to the recommendations of the ISO 13314 standard for compression testing of porous materials with relative densities lower than $50 \%$ (Standard ISO, 2011, [39]).


Figure 11. Tensile testing of lattice specimens with three cell orientations: (a) force-displacement and (b) stress-strain diagrams. 
The stress-strain diagrams shown in Figure 11b allows for a comparison of the monotonic tensile behavior of three differently oriented lattice structures (see Table 3 for selected characteristics). The reported elastic modulus $E$ is calculated from the linear part of the curves, with the highest value obtained for [111]-oriented specimens. The ultimate strength is the highest for [001]-oriented specimens. A yield stress was assigned to each specimen at a point where the stress-strain diagrams depart from their linear region, [001]-oriented specimens once again being the strongest. The lowest ductility, with intermediate stress characteristics, was seen with [111]-oriented specimens.

Table 3. Mechanical properties of lattice specimens evaluated from tensile tests.

\begin{tabular}{ccccc}
\hline Orientation & $\begin{array}{c}\text { Young's Modulus } \\
\boldsymbol{E} \mathbf{( G P a )}\end{array}$ & $\begin{array}{c}\text { Yield Stress } \sigma_{y} \\
\mathbf{( M P a})\end{array}$ & $\begin{array}{c}\text { Ultimate Tensile } \\
\text { Strength } \sigma_{\text {UTS }}(\mathbf{M P a})\end{array}$ & $\begin{array}{c}\text { Elongation at } \\
\text { Break } \varepsilon_{\max } \mathbf{( \% )}\end{array}$ \\
\hline$[001]$ & 6.8 & 32 & 49 & 4.0 \\
{$[011]$} & 7.7 & 28 & 42 & 3.1 \\
{$[111]$} & 11.3 & 31 & 40 & 0.3 \\
\hline
\end{tabular}

Fracture Surfaces of the Lattice Specimens

The fracture patterns of the differently oriented lattice specimens can provide useful information on the failure mechanisms acting at the level of struts and indicate the weakest planes for each orientation. It can be observed in Figure 12 that each lattice orientation presents a specific fracture pattern, which is similar for the monotonic and the fatigue testing. (Fatigue tests results are reported in the next section.) The observations suggest that there is a competition between several planes through which the final fracture occurs. For the [011] orientation, the fracture propagates along a plane perpendicular to the struts oriented by $35.26^{\circ}$ with respect to the loading direction, indicating a weak link for the [011] orientation under tension. The [111]-oriented specimens break in a very well-defined plane perpendicular to the loading direction. From observing the broken struts, it seems that the fracture is produced by normal loading of the vertical struts, which corresponds to the smallest net cross section of the specimen (Figure 7). The [001] oriented specimens offer the most irregular fracture plane.

The fracture patterns observed for each lattice orientation can be related to the existence of well-defined weak regions limited by planes normal to the strut directions, which are schematized in Figures 13a and 13b for [001]- and [011]-oriented specimens, respectively. In these systems, two neighboring planar regions are separated by a space with the lowest resistance to shear forces. Under uniaxial tensile test conditions, there are four equivalent weak systems for the [001]-oriented cell specimens labeled as 1, 2, 3, and 4 in Figure 13a. In the case of the [011]-oriented cell specimens, two of the four struts are perpendicular to the loading direction, and they are not subjected to shear forces. The [011] orientation contains, therefore, only two weak systems (represented as 1 and 2 in Figure 13b). In the [111]-oriented specimens, the loading direction coincides with one of the four strut orientations, and the other three orientations define equivalent weak systems. However, in this case, the fracture is initiated by normal forces applied to the vertical struts rather than by the bending moments, since the shear forces resolved on all other weak systems are notably smaller than their normal equivalents; the angle between them and the loading direction being as small as $19.47^{\circ}$. The existence of these planar weak systems explains the damage localization usually referred to as macroscopic shear or crush bands observed in experimental works and reproduced by numerical simulations involving compressive and tensile monotonic and cyclic study cases [33,40,41]. 


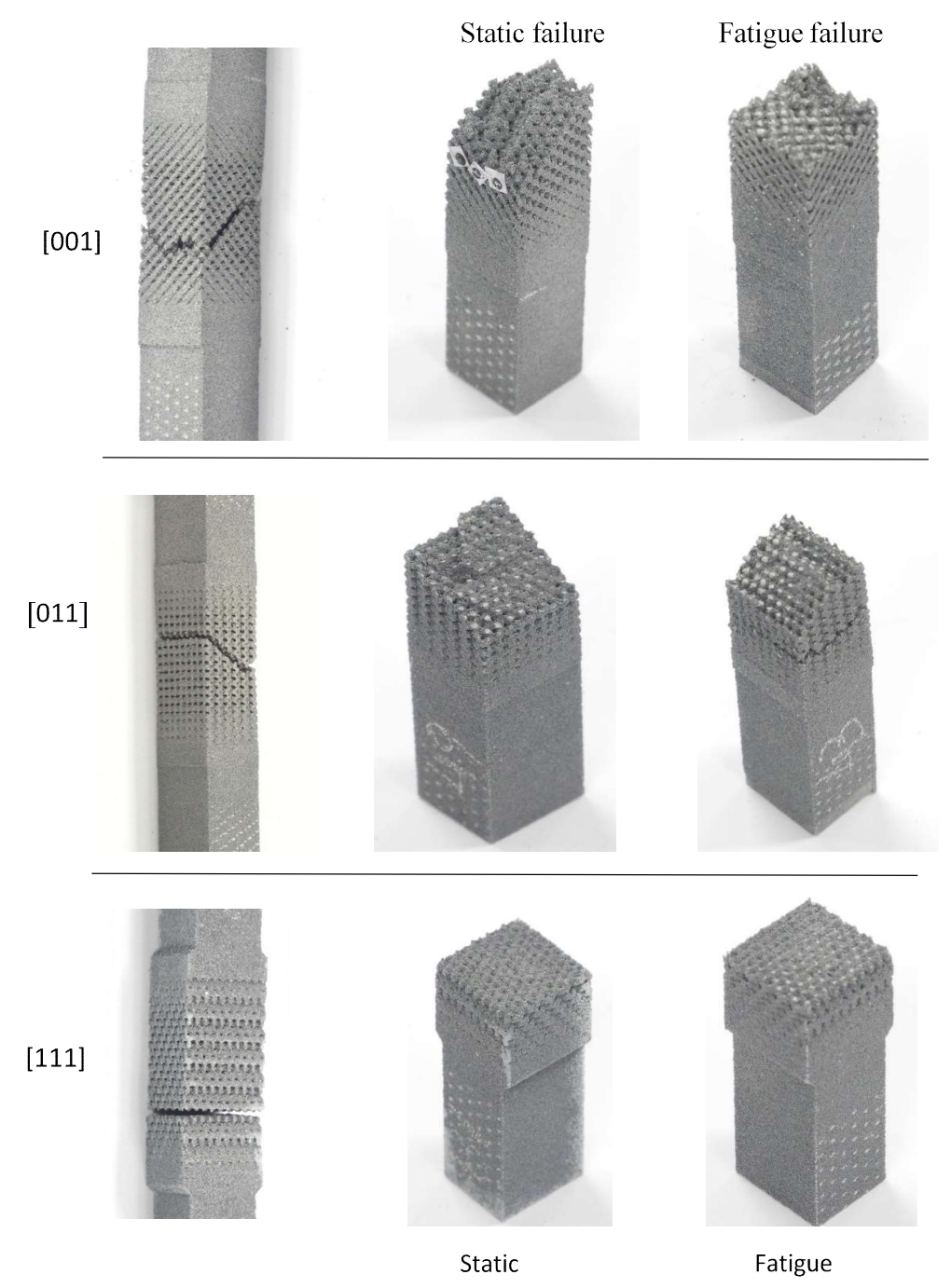

Figure 12. Images of the fracture of the different lattice specimens.
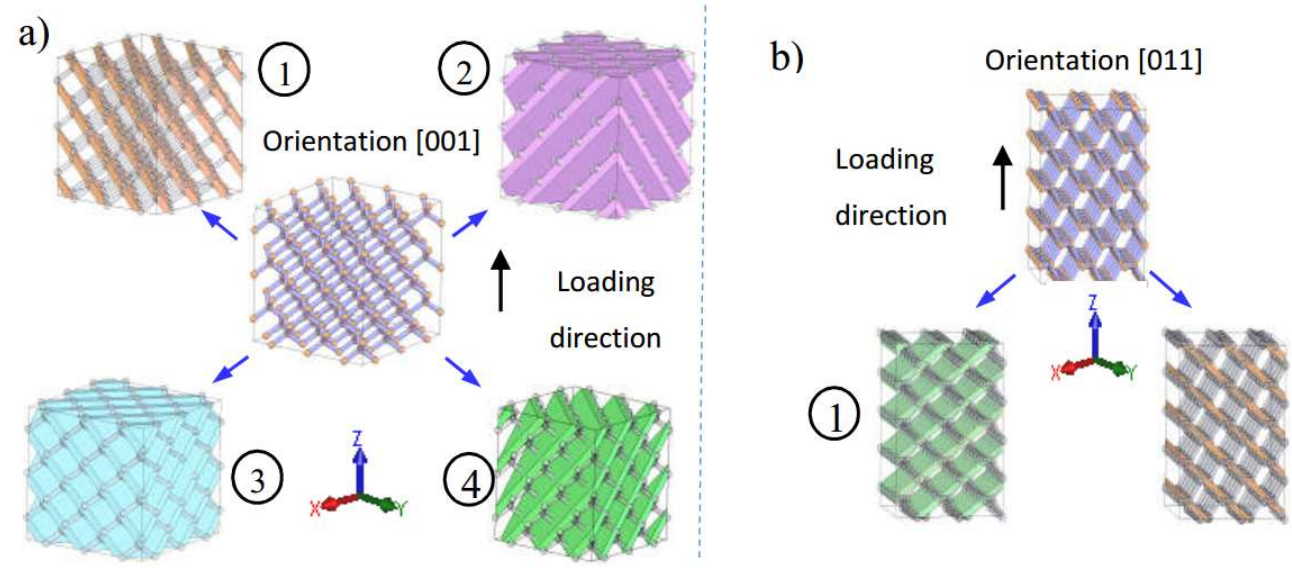

Figure 13. Representation of weak systems defined by struts directions. (a) Four equivalent strut orientation of [001]-oriented specimens and (b) two weak strut orientations of [011]-oriented specimens. 


\subsection{Fatigue Testing}

\subsubsection{Damage Evolution}

Fatigue testing was performed with notched and plain fully dense specimens, as well as with specimens bearing the differently oriented diamond lattices. The typical behavior of these specimens is represented by the plot in Figure 14, where the displacements corresponding to the cyclic peak and valley positions, as well as to the peak-to-valley differences, are plotted as functions of the number of cycles. A simultaneous increase in the peak and valley displacements reveals a so-called ratcheting behavior associated with the accumulation of plasticity [26]. An increase in the difference between the peak and the valley displacements is related to a decrease in specimen stiffness, which in turn is associated with a gradual growth of existing defects or a nucleation of the new ones. The three stages roughly defined in Figure 14 resemble the commonly observed stages of plastic strain evolution during a creep test. During the 1st stage, the rate of plastic strain accumulation decreases down to a stationary value. During the second stage, the strain rate can be considered constant. Finally, during the third stage, the strain rate accelerates until failure occurs. This three-stage pattern of the gradual strain accumulation is widely reported for the compression fatigue of lattice or foam structures [40,41] and will be presented in this study for the lattice specimens only.

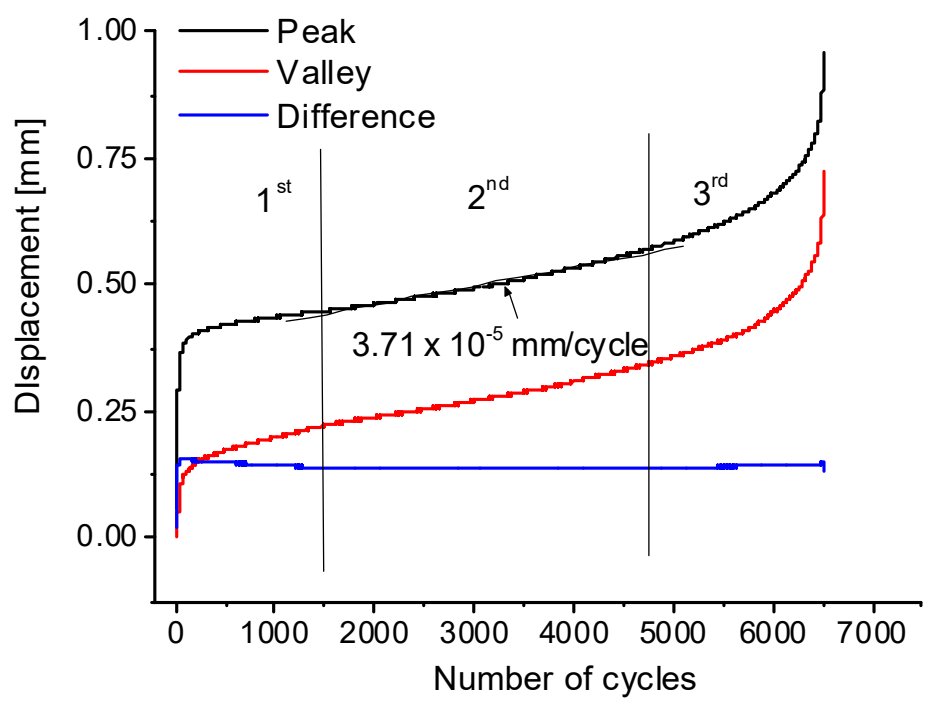

Figure 14. Evolutions of the peak and valley displacements, and of their difference (peak-to-valley) with respect to the number of cycles; the data correspond to specimen [111], with $\sigma_{\max } / \sigma_{\text {yield }}=1.2$.

In Figure 15, selected plots obtained for each lattice orientation are included. It is possible to compare the peak displacements (black lines), the valley displacements (red lines), and their peak-to-valley differences (blue lines) for tests with $\sigma_{\max } / \sigma_{\text {yield }}=1.2,0.8$, and 0.4 . While all three deformation stages can be clearly observed for [001]- and [011]-oriented specimens, [111]-oriented specimens seem to reach the fracture just before or shortly after a third stage of deformation is reached. The observations are consistent with the low ductility values obtained in tensile tests for [111]-oriented specimens (Figure 11). 


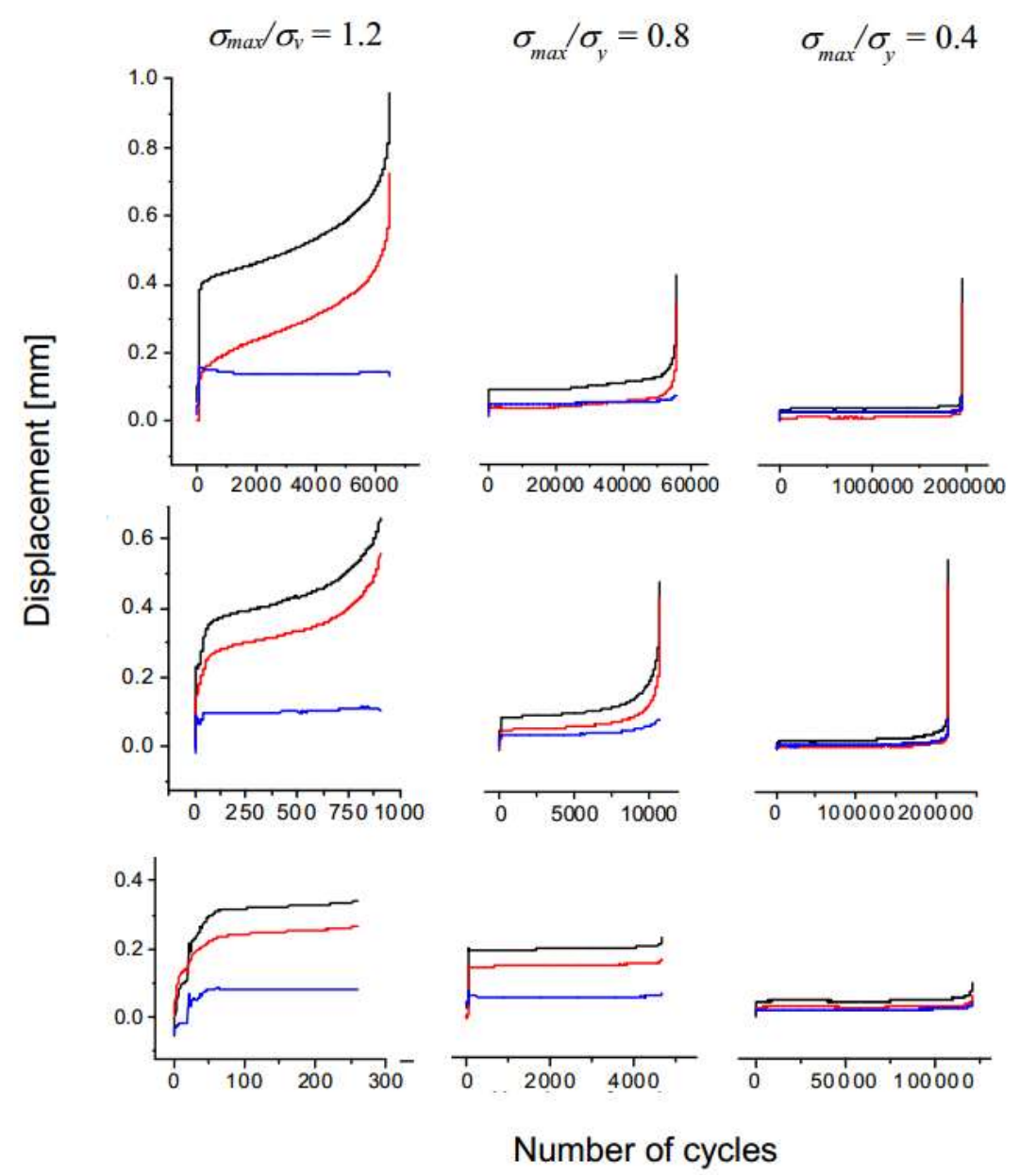

Figure 15. Plots of the peak (black) and valley (red) displacements, and their difference (blue) for analysis of the damage evolution for three orientations.

The difference between the peak and the valley displacements, which indicates an increase in the size and quantity of defects, seems to remain stable along the tests, while showing an increase in the third stage, clearly observable for $\sigma_{\max } / \sigma_{\text {yield }}=0.8$ and 0.4 , in the case of [001]- and [011]-oriented specimens. In any case, ratcheting is the predominant mechanism of the damage evolution during the second stage.

The rates at which the peak displacements are increased, measured for the second stage of the fatigue testing, are plotted in Figure 16 with respect to the maximum applied stress $\sigma_{\max }$. A power law relationship can therefore be established:

$$
\frac{\Delta X}{\Delta N}=C \sigma^{n}
$$

These results show that [001]-oriented specimens exhibit the highest resistance to damage accumulation. In contrast, [011]-oriented specimens are the worst, their damage rate being 1.5 orders of magnitude higher than that of [001]-oriented specimens. The ratcheting rate of [111]-oriented specimens is lower than that of [011]-oriented specimens but higher than that of [001]-oriented specimens. Even though the ratcheting rate of [111]-oriented specimens follows two different power law regimes for two different stress ranges, exponents $n$ fitted to all three sets of data denote a strong dependence of the ratcheting on the maximum applied stress for all the lattice orientations, ranging between 5.3 and 9.4. 




Figure 16. Peak displacement rates in the second stage of damage accumulation as a function of $\sigma_{\max }$.

\subsubsection{S-N Diagrams}

Figure 17a,b includes the S-N bi-logarithmic plots corresponding to the fatigue lives of the fully dense and lattice specimens as functions of the maximum applied stress $\sigma$. A linear fitting corresponding to a Basquin law of type

$$
\sigma_{\max }=D N^{m}
$$

was applied to all the fatigue data. The values of the constants $D$ and $m$ are included in the plot labels. Comparing the results obtained with the plain and the notched specimens, it is possible to conclude with respect to the detrimental effect of the notch (Figure 17a). Regarding the lattice specimens, Figure 17b shows that [001]-oriented specimens clearly outperform [011]- and [111]-oriented specimens in terms of their fatigue resistance, with the difference between the last two being insignificant.
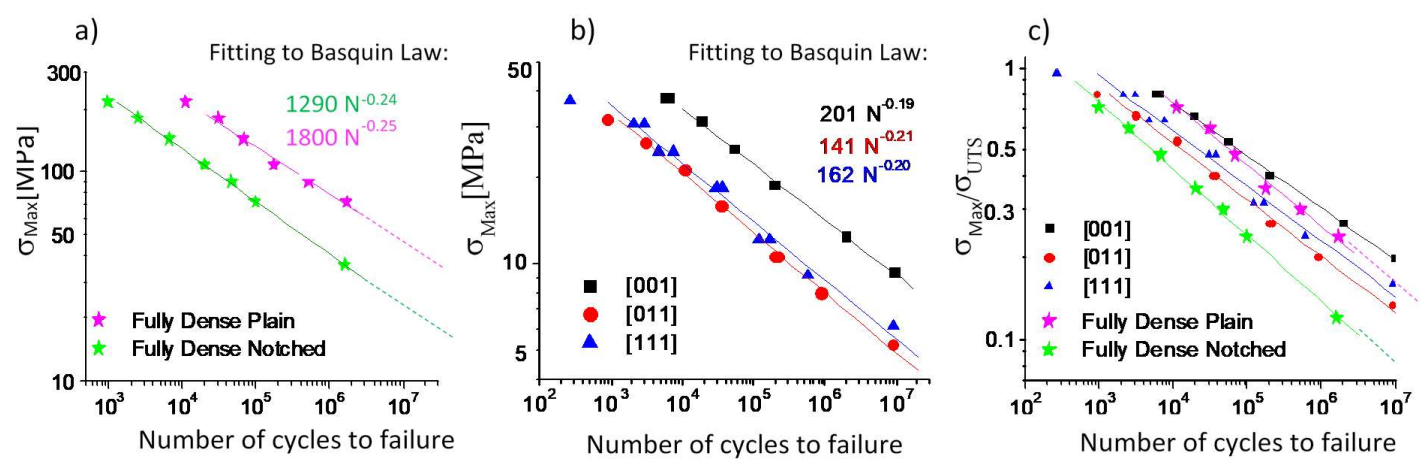

Figure 17. Fatigue lives as functions of maximum stress of the (a) plain/notched dense specimens and (b) lattice specimens; (c) fatigue lives of dense and lattice specimens as function of the maximum stress normalized with $\sigma_{U T S}$.

In Figure 17c, the fatigue lives of dense and lattice specimens are all compared by utilizing, as a variable, the maximum stress in a cycle $\sigma$ normalized by the corresponding ultimate strength $\sigma_{\text {UTS }}$. This representation allows one to affirm that lattice [001]-oriented specimens outperform fully dense plain specimens in terms of normalized fatigue resistance. The normalized fatigue resistance of [011]and [111]-oriented specimens is lower than that of the plain specimens and higher than that of the notched specimens. The notched specimens clearly do not perform as well in this representation. 
3.2.3. Effective Stresses, Fatigue Concentration, and Notch Sensitivity Factors in Notched and Lattice Specimens

In Figure 17c, the normalization of the maximum stress in a cycle by the ultimate strength allows for a direct comparison of the fatigue resistance of the dense and lattice specimens of this study. An alternative approach for such a comparison is also possible using the definition of an effective stress, which can be calculated by dividing the applied load by a minimum net cross section of the specimens (see values of $A_{\min A S}$ in Table 1). This effective stress corresponds to a mean normal stress acting on the smallest (weakest) cross section of a lattice specimen along its loading direction.

Using this definition, the fatigue lives of all the tested specimens are compared in Figure 18, where the effective stresses are calculated using the minimum net cross-section areas reported in Table 1 (for the plain and notched dense specimens, their effective stresses are the same as $\sigma$ in Figure 17a). In agreement with this representation, the fatigue resistance of [111]-oriented specimens appears to be significantly higher than that of [001]- and [011]-oriented specimens and almost identical to that of their notched counterparts. The fully dense plain specimens are clearly the best performing, thus reflecting the detrimental effect of stress concentrations in lattice and notched specimens on their effective fatigue resistance.

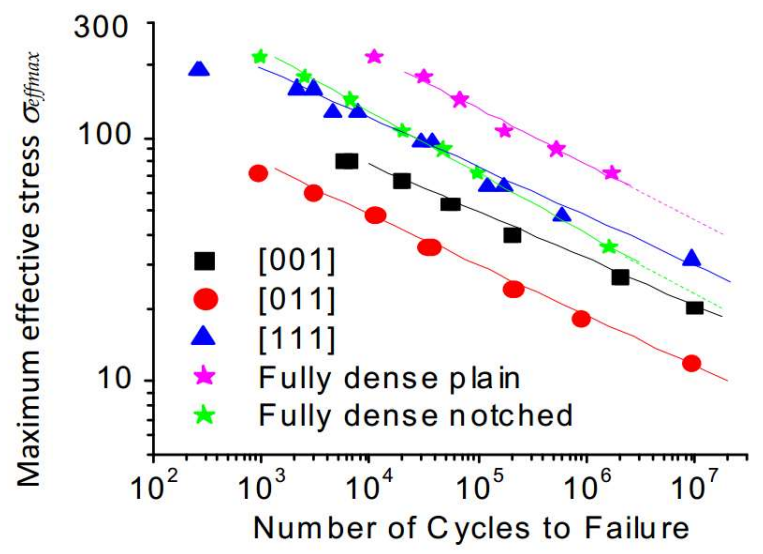

Figure 18. S-N representation of fatigue tests as a function of the effective stress evaluated with the minimum net cross sections.

Next, the endurance limit of each specimen $\sigma_{e}$, defined as the maximum effective stress corresponding to a fatigue life of $10^{7}$ cycles, can be calculated using the Basquin law fitting (Table 4). The endurance limit in terms of effective stresses are finally used to calculate the fatigue stress concentration factor, $K_{f}$, assuming the endurance limit of plain specimen, $\sigma_{e}(p l)$ as the reference value.

$$
K_{f}=\frac{\sigma_{e}(p l)}{\sigma_{e}}
$$

Table 4. Basquin law parameters $D$ and $m$, endurance limits, and fatigue stress concentration factors.

\begin{tabular}{ccccc}
\hline Specimens & $\boldsymbol{D} \mathbf{( M P a )}$ & $\boldsymbol{m}$ & $\left.\sigma_{\boldsymbol{e}} \mathbf{( M P a}\right)$ & $\boldsymbol{K}_{\boldsymbol{f}}$ \\
\hline Plain & 1800 & -0.23 & 44 & 1 \\
Notched & 1290 & -0.24 & 23 & 1.9 \\
[001] & 446 & -0.19 & 20 & 2.2 \\
[011] & 324 & -0.21 & 11 & 4 \\
[111] & 741 & -0.20 & 29 & 1.5 \\
\hline
\end{tabular}




\section{Discussion}

The results obtained in the framework of this study provide useful experimental information for the design of complex AM components, more specifically of lattice structures subjected to tension loads. This last aspect has not been extensively studied in the literature and constitutes the main contribution of this work. One of the points we aimed to highlight was the overall suitability of the L-PBF technology to the manufacture of lattice-containing components. Such components made of an AlSiMg alloy exhibit an irregular surface finish, with higher surface roughness and a greater number of defects than what was reported for TiAlV [6]. Despite these drawbacks, the components kept their integrity during both monotonic and cyclic mechanical loading, even for the [011] and [111] orientations for which the minimum overhang angle was far below that for the [001] orientation. Therefore, this manufacturing process can be considered for applications where the functionality of lattice structures is required, and the properties of the AlSiMg alloy are suitable.

The CT analysis performed in Section 2.5 indicated that the total volume of internal pores was kept below $0.24 \%$ for all the specimens of the study, the value that can be considered too low to impair the functional properties of L-PBF components [36]. Moreover, since no significant differences in porosity levels of the differently oriented lattice structures were measured, we believe that in our study the struts orientation did not significantly impact the defects distribution as was observed by Delroisse et al. [22]. That said, a special investigation must be carried out to assess the impact of such a process-induced porosity on the static and, especially, fatigue behavior of L-PBF AlSi10\%Mg components. The same CT analysis showed that the cross sections of the manufactured specimens were systematically thinner than their CAD origins (the former representing a fraction of 0.81 to 0.925 of the latter).

Monotonic tensile testing of lattice specimens revealed a notable dependence of their mechanical properties on cell orientation. The ratio between the Young's moduli of the [111] and the [001] orientations was 1.67 , which, when compared with crystals with cubic symmetry, corresponds to a significant degree of elastic anisotropy [42]. It must, however, be mentioned that no agreement exists on the degree of the diamond cell anisotropy. In some works, this cell is assumed isotropic [33], while the contrary is suggested in other works $[43,44]$. The second position seems to be more convincing, since it is well accepted that the elastic properties of crystals with diamond geometry exhibit directional dependence [42,45]. Regarding the mechanical strength, the corresponding values for [001]-oriented specimens were almost $20 \%$ higher than that for [111]-oriented specimens. The ductility and the energy to fracture were higher in [001]-oriented specimens than in [011]-oriented specimens, with both quantities being dramatically reduced for [111]-oriented specimens. These results are consistent with the fact that the fracture surface areas associated with each orientation decrease in the same order: [001], [011], and [111] (see the illustrations of fracture surfaces in Figure 12).

By comparing the fatigue resistance of the lattice structures in terms of the applied stresses, it can be concluded that the [001] orientation is the most favorable, resulting in fatigue lives that are $\sim 30 \%$ higher than for the other orientations (Figure 17b). Additionally, [001]-oriented specimens showed the highest resistance to ratcheting, being almost 1.5 orders of magnitude more resistant than [011]-oriented specimens, within the tested stress range. With respect to the final fracture, both the [001]- and [011]-oriented specimens exhibited a well-defined third stage of deformation, with a notable increase in the rate of ratcheting, in contrast with [111]-oriented specimens, which presented an abrupt final fracture. This brittle-like behavior of [111]-oriented specimens during their cyclic testing is in line with the corresponding results of monotonic testing, and prevents the possibility of predicting an imminent fracture of such lattice structures by observing an accumulation of their plastic deformation during cycling.

The results obtained in this work do not allow a determination of whether the cell orientation dependence is mainly related to the intrinsic anisotropy of the diamond cell or that it has mainly to do with the manufacturing aspects. Note, however, that the differences in the levels of internal porosity or surface roughness among the three studied orientations were not sufficiently significant to 
explain such a systematic difference in the fatigue lives. A detailed microstructural analysis is however mandatory to clarify this aspect.

Plotting the fatigue lives as functions of the normalized maximum stresses $\left(\sigma_{\max } / \sigma_{\text {UTS }}\right)$ allows a comparison of specimens with different densities, cell geometries, and materials. The compressive fatigue properties of porous materials are frequently reported using such a representation, normalizing the applied stress by the so-called plateau stress (see e.g. [27,46,47]). Following this approach, it was found that [001]-oriented specimens performs even better than the plain specimens, while the S-N data of [011]- and [111]-oriented specimens lie in-between those of their plain and notched counterparts. The data reported here can eventually be incorporated into an extended study involving other densities, cells geometries, and materials. It is worth pointing out that this comparison is made relatively to the ultimate strength, which is measured independently for each kind of the specimens and under pseudostatic conditions. Therefore, from this comparison, it is not possible to conclude on how some particular aspects, such as the surface roughness or the stress concentrations, affect the fatigue behavior of each kind of specimens.

A rough estimation of the stress concentrations related to the geometrical characteristics of each specimen and of their impact on the fatigue resistance can be made by comparing the S-N diagrams, where $S$ represents the level of acting effective stresses (Figure 18). A similar procedure was used by Huynh et al. [29] to compare the fatigue lives of lattice and dense specimens. The calculations of the fatigue stress concentration factors $K_{f}$ from these fatigue lives, assuming the plain specimens as the reference, indicate that, for [111]-oriented specimens, local peak stresses corresponding to mean effective stresses are lower than those for [001]- and [011]-oriented specimens. The local stresses calculated here should not be confused with those obtained using the local stress approach of Hooreweder et al. [48], by which the maximum tensile stresses acting on individual struts were calculated as a direct combination of stresses resulted from normal forces and bending moments. Such an approach cannot be applied in the case of small strut length-to-thickness ratios as those studied in this work.

Although stress concentration factors are conceived to study simple geometries with stress risers like holes or notches, the evolution of local stresses in lattice structures can be a result of a combination of different loading modes, such as bending and tension in struts, which make up these structures. A further study of the same lattice specimens under compression would be useful for distinguishing between the two effects, since, while bending moments would cause equal tensile stresses, the normal component of the force would change to compression stresses.

Notched specimens deserve particular mention; the calculated static stress concentration factor $K_{e}=2.33$ (Figure 10a) is significantly higher than the corresponding fatigue stress concentration factor $K_{f}=1.6$. This misfit is related to the fact that the $K_{e}$ calculations do not take into account all the phenomena arising during fatigue testing, which may attenuate the ratio between the peak stresses generated in the notched and the plain specimens. For example, for the $K_{e}$ evaluation, the stress redistribution due to plasticity during monotonic loading can differ from that produced during the cyclic loading. Additionally, the influence of the surface roughness, which may affect the fatigue resistance of the plain and the notched specimens differently, cannot be simulated by such numerical calculations.

\section{Conclusions}

This work provides experimental data on the mechanical behavior, and more specifically the fatigue resistance under tension of $\sim 44-45 \%$ of relatively dense diamond cell lattice structures made of AlSiMg alloy, using laser powder bed metal fusion. The results are reported together with information obtained from fully dense plain and notched tensile specimens made of the same material using the same manufacturing technology.

A significant dependence on the orientation of diamond cells was found for the mechanical properties measured under both monotonic and cyclic loading conditions. The ultimate strength for 
the [001] orientation came up almost $20 \%$ higher than for the other orientations. Specimens with the [111] orientation showed a notably lower ductility.

The fatigue lives of specimens with the [001] orientation were $~ 30 \%$ higher than those of [011]and [111]-oriented specimens with the same level of applied stresses. In the same vein, [001]-oriented specimens exhibited ratcheting rates almost 1.5 orders of magnitude lower than [011]-oriented specimens.

The stress concentration factors evaluated in terms of effective stresses range from highest to lowest as follows: [011], [001], and [111]. Only [111]-oriented specimens showed a fatigue concentration factor lower than that obtained for the dense notched specimen.

Acknowledgments: The work was performed at ETS in the Laboratory on Shape Memory Alloys and Intelligent Systems (LAMSI) with invaluable assistance from M. Letenneur, J.R. Poulin-Masson, and B. Jetté. H. Soul especially acknowledges CONICET (Argentina) for its financial support. Financial support from the NSERC Discovery program is acknowledged by P. Terriault and V. Brailovski.

Author Contributions: This work plan was developed by Hugo Soul to meet the study objectives defined by Patrick Terriault and Vladimir Brailovski. The specimen design and alloy selection were carried out by all the coauthors based upon the state of the art, previous research of Patrick Terriault and Vladimir Brailovski, and the current trends in the field. The design, fabrication, and testing of the specimens were performed by $\mathrm{H}$. Soul with the aid of Patrick Terriault. Vladimir Brailovski, and Patrick Terriault contributed to the data organization, results interpretation, and manuscript review.

Conflicts of Interest: The authors declare no conflicts of interest.

\section{References}

1. Ashby, M. Hybrid materials to expand the boundaries of material-property space. J. Am. Ceram. Soc. 2011, 94 (Suppl. 1). [CrossRef]

2. Evans, A.G.; Hutchinson, J.W.; Ashby, M.F. Multifunctionality of cellular metal systems. Prog. Mater. Sci. 1998, 43, 171-221. [CrossRef]

3. Maiti, A.; Small, W.; Lewicki, J.P.; Weisgraber, T.H.; Duoss, E.B.; Chinn, S.C.; Pearson, M.A.; Spadaccini, C.M.; Maxwell, R.S.; Wilson, T.S. 3D printed cellular solid outperforms traditional stochastic foam in long-term mechanical response. Sci. Rep. 2016, 6, 24871. Available online: http:/ /www.nature.com/articles/srep24871 (accessed on 1 November 2017). [CrossRef] [PubMed]

4. Simoneau, C.; Brailovski, V.; Terriault, P. Design, manufacture and tensile properties of stochastic porous metallic structures. Mech. Mater. 2016, 94, 26-37. [CrossRef]

5. Van der Stok, J.; Wang, H.; Yavari, S.A.; Siebelt, M.; Sandker, M.; Waarsing, J.H.; Verhaar, J.A.; Jahr, H.; Zadpoor, A.A.; Leeuwenburgh, S.C.; et al. Enhanced Bone Regeneration of Cortical Segmental Bone Defects Using Porous Titanium Scaffolds Incorporated with Colloidal Gelatin Gels for Time- and Dose-Controlled Delivery of Dual Growth Factors. Tissue Eng. Part A 2013, 19, 2605-2614. [CrossRef] [PubMed]

6. Wang, X.; Xu, S.; Zhou, S.; Xu, W.; Leary, M.; Choong, P.; Qian, M.; Brandt, M.; Xie, Y.M. Topological design and additive manufacturing of porous metals for bone scaffolds and orthopaedic implants: A review. Biomaterials 2016, 83, 127-141. [CrossRef] [PubMed]

7. Maloney, K.J.; Fink, K.D.; Schaedler, T.A.; Kolodziejska, J.A.; Jacobsen, A.J.; Roper, C.S. Multifunctional heat exchangers derived from three-dimensional micro-lattice structures. Int. J. Heat Mass Transf. 2012, 55, 2486-2493. [CrossRef]

8. Hurt, C.; Brandt, M.; Priya, S.S.; Bhatelia, T.; Patel, J.; Selvakannan, P.; Bhargava, S. Combining additive manufacturing and catalysis: A review. Catal. Sci. Technol. 2017, 7, 3421-3439. [CrossRef]

9. Mahshid, R.; Hansen, H.N.; Højbjerre, K.L. Strength analysis and modeling of cellular lattice structures manufactured using selective laser melting for tooling applications. Mater. Des. 2016, 104, $276-283$. [CrossRef]

10. Ullah, I.; Brandt, M.; Feih, S. Failure and energy absorption characteristics of advanced 3D truss core structures. Mater. Des. 2016, 92, 937-948. [CrossRef]

11. Maskery, I.; Aboulkhair, N.T.; Aremu, A.O.; Tuck, C.J.; Ashcroft, I.A.; Wildman, R.D.; Hague, R.J. A mechanical property evaluation of graded density Al-Si10-Mg lattice structures manufactured by selective laser melting. Mater. Sci. Eng. A 2016, 670, 264-274. [CrossRef] 
12. Evans, A.G.; Hutchinson, J.W.; Fleck, N.A.; Ashby, M.F.; Wadley, H.N.G. The topological design of multifunctional cellular metals. Prog. Mater. Sci. 2001, 46, 309-327. [CrossRef]

13. Zadpoor, A.A.; Hedayati, R. Analytical relationships for prediction of the mechanical properties of additively manufactured porous biomaterials. J. Biomed. Mater. Res. Part A 2016, 104, 3164-3174. [CrossRef] [PubMed]

14. Mazur, M.; Leary, M.; McMillan, M.; Sun, S.; Shidid, D.; Brandt, M. 5-Mechanical properties of Ti6Al4V and AlSi12Mg lattice structures manufactured by Selective Laser Melting (SLM). In Laser Additive Manufacturing; Woodhead Publishing Series in Electronic and Optical Materials; Elsevier: Amsterdam, The Netherlands, 2017; pp. 119-161.

15. Hedayati, R.; Sadighi, M.; Mohammadi-Aghdam, M.; Zadpoor, A.A. Analytical relationships for the mechanical properties of additively manufactured porous biomaterials based on octahedral unit cells. Appl. Math. Model. 2017, 46, 408-422. [CrossRef]

16. Quevedo González, F.J.; Nuño, N. Finite element modelling approaches for well-ordered porous metallic materials for orthopaedic applications: Cost effectiveness and geometrical considerations. Comput. Methods Biomech. Biomed. Eng. 2016, 19, 845-854. [CrossRef] [PubMed]

17. Smith, M.; Guan, Z.; Cantwell, W.J. Finite element modelling of the compressive response of lattice structures manufactured using the selective laser melting technique. Int. J. Mech. Sci. 2013, 67, 28-41. [CrossRef]

18. Bagehorn, S.; Wehr, J.; Maier, H.J. Application of mechanical surface finishing processes for roughness reduction and fatigue improvement of additively manufactured Ti-6Al-4V parts. Int. J. Fatigue 2017, 102, 135-142. [CrossRef]

19. Leon, A.; Aghion, E. Effect of surface roughness on corrosion fatigue performance of AlSi10Mg alloy produced by Selective Laser Melting (SLM). Mater. Charact. 2017, 131, 188-194. [CrossRef]

20. Aboulkhair, N.T.; Maskery, I.; Tuck, C.; Ashcroft, I.; Everitt, N.M. Improving the fatigue behaviour of a selectively laser melted aluminium alloy: Influence of heat treatment and surface quality. Mater. Des. 2016, 104, 174-182. [CrossRef]

21. Brandl, E.; Heckenberger, U.; Holzinger, V.; Buchbinder, D. Additive manufactured AlSi10Mg samples using Selective Laser Melting (SLM): Microstructure, high cycle fatigue, and fracture behavior. Mater. Des. 2012, 34, 159-169. [CrossRef]

22. Delroisse, P.; Jacques, P.J.; Maire, E.; Rigo, O.; Simar, A. Effect of strut orientation on the microstructure heterogeneities in AlSi10Mg lattices processed by selective laser melting. Scr. Mater. 2017, 141, 32-35. [CrossRef]

23. Tang, M.; Pistorius, P.C. Oxides, porosity and fatigue performance of AlSi10Mg parts produced by selective laser melting. Int. J. Fatigue 2017, 94, 192-201. [CrossRef]

24. Sutton, A.T.; Kriewall, C.S.; Leu, M.C.; Newkirk, J.W. Powder characterisation techniques and effects of powder characteristics on part properties in powder-bed fusion processes. Virtual Phys. Prototyp. 2017, 12, 3-29. [CrossRef]

25. Sing, S.L.; Wiria, F.E.; Yeong, W.Y. Selective laser melting of lattice structures: A statistical approach to manufacturability and mechanical behavior. Robot. Comput. Integr. Manuf. 2018, 49, 170-180. [CrossRef]

26. Zhao, S.; Li, S.J.; Hou, W.T.; Hao, Y.L.; Yang, R.; Misra, R.D.K. The influence of cell morphology on the compressive fatigue behavior of Ti-6Al-4V meshes fabricated by electron beam melting. J. Mech. Behav. Biomed. Mater. 2016, 59, 251-264. [CrossRef] [PubMed]

27. Yavari, S.A.; Ahmadi, S.M.; Wauthle, R.; Pouran, B.; Schrooten, J.; Weinans, H.; Zadpoor, A.A. Relationship between unit cell type and porosity and the fatigue behavior of selective laser melted meta-biomaterials. J. Mech. Behav. Biomed. Mater. 2015, 43, 91-100. [CrossRef] [PubMed]

28. Wauthle, R.; Vrancken, B.; Beynaerts, B.; Jorissen, K.; Schrooten, J.; Kruth, J.P.; Van Humbeeck, J. Effects of build orientation and heat treatment on the microstructure and mechanical properties of selective laser melted Ti6Al4V lattice structures. Addit. Manuf. 2015, 5, 77-84. [CrossRef]

29. Huynh, L.; Rotella, J.; Sangid, M.D. Fatigue behavior of IN718 microtrusses produced via additive manufacturing. Mater. Des. 2016, 105, 278-289. [CrossRef]

30. Dumas, M.; Terriault, P.; Brailovski, V. Modelling and characterization of a porosity graded lattice structure for additively manufactured biomaterials. Mater. Des. 2017, 121, 383-392. [CrossRef]

31. EOS GmbH. Electro Optical Systems. Material Data Sheet: EOS Aluminium AlSi10Mg. 2014. Available online: http:/ / gpiprototype.com/images/PDF/EOS_Aluminium_AlSi10Mg_en.pdf (accessed on 10 December 2017). 
32. Pilkey Walter, P.D. Petersons Stress Concentration Factors, 3rd ed.; John Wiley \& Sons: Hoboken, NJ, USA, 2008; 560p.

33. Ahmadi, S.M.; Campoli, G.; Yavari, S.A.; Sajadi, B.; Wauthle, R.; Schrooten, J.; Weinans, H.; Zadpoor, A.A. Mechanical behavior of regular open-cell porous biomaterials made of diamond lattice unit cells. J. Mech. Behav. Biomed. Mater. 2014, 34, 106-115. [CrossRef] [PubMed]

34. Fabbrocino, F.; Amendola, A. Discrete-to-continuum approaches to the mechanics of pentamode bearings. Compos. Struct. 2017, 167, 219-226. [CrossRef]

35. Jetté, B.; Brailovski, V.; Dumas, M.; Simoneau, C.; Terriault, P. Femoral stem incorporating a diamond cubic lattice structure: Design, manufacture and testing. J. Mech. Behav. Biomed. Mater. 2018, 77, 58-72. [CrossRef] [PubMed]

36. Gong, H.; Rafi, K.; Gu, H.; Starr, T.; Stucker, B. Analysis of defect generation in Ti-6Al-4V parts made using powder bed fusion additive manufacturing processes. Addit. Manuf. 2014, 1, 87-98. [CrossRef]

37. Liu, L.; Kamm, P.; García-Moreno, F.; Banhart, J.; Pasini, D. Elastic and failure response of imperfect three-dimensional metallic lattices: The role of geometric defects induced by Selective Laser Melting. J. Mech. Phys. Solids 2017, 107, 160-184. [CrossRef]

38. Geng, X.; Ma, L.; Liu, C.; Zhao, C.; Yue, Z. A FEM study on mechanical behavior of cellular lattice materials based on combined elements. Mater. Sci. Eng. A 2018, 712, 188-198. [CrossRef]

39. ISO Standard. ISO 13314 Mechanical Testing of Metals, Ductility Testing, Compression Test for Porous and Cellular Metals; Ref Number ISO 13314; ISO: Geneva, Switzerland, 2011; pp. 1-7. Available online: www.iso.org (accessed on 9 October 2017).

40. Harte, A.M.; Fleck, N.A.; Ashby, M.F. Fatigue failure of an open cell and a closed cell aluminum alloy foam. Acta Mater. 1999, 47, 2511-2524. [CrossRef]

41. Li, F.; Li, J.; Huang, T.; Kou, H.; Zhou, L. Compression fatigue behavior and failure mechanism of porous titanium for biomedical applications. J. Mech. Behav. Biomed. Mater. 2017, 65, 814-823. [CrossRef] [PubMed]

42. Hosford, W.F. The Mechanics of Crystals and Textured Polycrystals; Oxford University Press: New York, NY, USA, 1993; 248p.

43. Naegelin, V. Rapport de Projet l'École de Technologie Supérieure Comme Exigence Partielle À l'Obtention de la Modélisation par Éléments Finis de Matériaux Poreux; 2014 Creative Commons License; Bureau des Cycles Superieurs, Ecole de Technologie Superieure: Montreal, QC, Canada, 2014.

44. Xu, S.; Shen, J.; Zhou, S.; Huang, X.; Xie, Y.M. Design of lattice structures with controlled anisotropy. Mater. Des. 2016, 93, 443-447. [CrossRef]

45. Güler, E.; Güler, M. Elastic and Mechanical Properties of Cubic Diamond under Pressure. Chin. J. Phys. 2015, 53, 195-205.

46. Yavari, S.A.; Wauthle, R.; Van Der Stok, J.; Riemslag, A.C.; Janssen, M.; Mulier, M.; Kruth, J.P.; Schrooten, J.; Weinans, H.; Zadpoor, A.A. Fatigue behavior of porous biomaterials manufactured using selective laser melting. Mater. Sci. Eng. C 2013, 33, 4849-4858. [CrossRef] [PubMed]

47. Sugimura, Y.; Rabiei, A.; Evans, A.G.; Harte, A.M.; Fleck, N.A. Compression fatigue of a cellular Al alloy. Mater. Sci. Eng. A 1999, 269, 38-48. [CrossRef]

48. Van Hooreweder, B.; Kruth, J. Advanced fatigue analysis of metal lattice structures produced by Selective Laser Melting. CIRP Ann. Manuf. Technol. 2017, 66, 221-224. [CrossRef]

(C) 2018 by the authors. Licensee MDPI, Basel, Switzerland. This article is an open access article distributed under the terms and conditions of the Creative Commons Attribution (CC BY) license (http://creativecommons.org/licenses/by/4.0/). 